\title{
A CONCEPÇÃO DO RISCO NAS TEORIAS SOCIOLÓGICAS DE ULRICH BECK E ANTHONY GIDDENS
}

\section{THE CONCEPTION OF RISK IN THE SOCIOLOGICAL THEORIES OF ULRICH BECH AND ANTHONY GIDDENS}

\author{
André Luiz Pereira Spinieli ${ }^{*}$ \\ César Cardoso de Souza Neto ${ }^{* *}$
}

\begin{abstract}
RESUMO
A existência de uma sociedade contemporânea dos riscos expressa a ausência de controle humano sobre as catástrofes e incertezas fabricadas, em espaços onde imperam as leis da probabilidade. A chegada da pós-modernidade reforça a concatenação desenfreada de processos tecnológicos em áreas diversas e, consequentemente, fomenta o afastamento humano das certezas. Empregando-se o método dedutivo, mediante pesquisa bibliográfica de cunho exploratório, o objetivo geral deste escrito é apresentar uma análise comparativa sobre as concepções de risco nas teorias sociológicas de Ulrich Beck e Anthony Giddens. Parte-se da premissa de que ambos os autores concordam que a vida sob a presença do risco é inevitável para a sociedade pós-moderna, refém da desconfiança constante acerca da possibilidade de ocorrência de ameaças à integralidade da sociedade.
\end{abstract}

Palavras-chave: Risco. Ulrich Beck. Anthony Giddens. Sociedade. Sociologia.

\begin{abstract}
The existence of a contemporary society of risks expresses the absence of human control over catastrophes and manufactured uncertainties, in spaces where the laws of probability prevail. The arrival of post modernity reinforces the unbridled concatenation of technological processes in diverse areas and, consequently, promotes human distancing from certainties. Using the deductive method, through exploratory bibliographic research, the general objective of this writing is to present a comparative analysis on the conceptions of risk in the sociological theories of Ulrich Beck and Anthony Giddens. It is assumed that both authors agree that life in the presence of risk is inevitable for postmodern society, hostage to the constant suspicion that threats to the integrality of society may occur.
\end{abstract}

Keywords: Risk. Ulrich Beck. Anthony Giddens. Society. Sociology.

"Mestrando em Direito pelo Programa de Pós-Graduação em Direito pela Universidade Estadual Paulista

** Pós-doutorando em Direito pela Universidade de São Paulo 


\section{INTRODUÇÃO}

A partir da chegada da pós-modernidade, a ocorrência de catástrofes naturais, acidentes nucleares, conflitos armados e epidemias denuncia o aparecimento de um novo modelo de sociedade, que se contrapõe à típica sociedade industrial dos últimos séculos, da produção e distribuição de riqueza e na qual se passa para a lógica de distribuição dos riscos, denominada de sociedade de riscos (BECK, 2011, p. 23).

Primordialmente, Ulrich Beck parte da ideia de que a sociedade dos riscos possui como principal característica o fato de que as técnicas convencionais são absolutamente ineficientes e incapazes de anunciar os riscos aptos a atingir a saúde humana ou ao meio ambiente. Por outro lado, os riscos assumem um papel de centralidade nas novas produções mercadológicas, ao passo em que a sociedade do risco é também "a sociedade da ciência, da mídia e da informação" (BECK, 1998, p. 53).

A sistemática dos riscos contemporâneos é de tal gravidade que já não se respeitam mais os limites socioeconômicos das classes sociais. Nessa nova lógica da vida em sociedade, a ideia de classe social perde sua identidade e se dá espaço ao conceito de mobilidade social, o que essencialmente não encerra as desigualdades sociais, senão redefinem a individualização dos riscos sociais (BECK, 1998, p. 128). Dessa forma, os riscos podem ser considerados democráticos e globalizados, pois possuem o mesmo potencial para atingir ricos e pobres, ignorando qualquer separação entre classes sociais.

Por outro lado, a crítica lançada por Giddens parte do pressuposto de que os riscos na pós-modernidade são frutos da existência de um lado sombrio da modernidade, algo que fugiu completamente das pesquisas e previsões dos fundadores da sociologia clássica. Segundo Giddens, ao visitar as teses dos três autores clássicos da sociologia primeira, "as consequências da modernidade em termos de uma preocupação com os limites do uso da racionalidade científica e dos danos ambientais resultados das práticas industriais não foram considerados" (ALEXANDRE, 2000, p. 154).

Utilizando-se do método bibliográfico e comparativo, a partir da análise das obras centrais dos autores em destaque e de artigos científicos, obtidos por meio da inserção das palavras-chave em mecanismos de busca, utilizados como suportes para a sustentação das teses, este escrito visa analisar as concepções de sociedade do risco e suas implicações para o homem e o contexto social da pós-modernidade, com base nas teorias sociológicas de Ulrich Beck (1994-2015) e Anthony Giddens (1938-), cujos estudos se voltam à verificação das condições sociais na pós-modernidade.

O trabalho se encontra dividido em três capítulos, nos quais são apresentados os contornos da pós-modernidade e da sociedade do risco a partir das aproximações e divergências entre as teorias de Ulrich Beck e Anthony Giddens. No primeiro capítulo, abordam-se as ideias sobre a produção social dos riscos nos escritos do sociólogo alemão Ulrich Beck. No segundo estágio, tecem-se considerações sobre a concepção de risco sob a visão do britânico Anthony Giddens. Por fim, o texto apresenta convergências e divergências entre ambas as teses, destacando determinados exemplos práticos.

\section{PÓS-MODERNIDADE E A PRODUÇÃO SOCIAL DOS RISCOS EM BECK}

Nascido em 1944, o sociólogo alemão Ulrich Beck é um dos grandes defensores da noção segundo a qual a pós-modernidade ${ }^{1}$ sobrevive diante de um momento de ruptura histórica. Isso porque, como em outros tempos, quando também ocorreram rompimentos históricos, citando-se como exemplo a transmutação do feudalismo para a sociedade industrial, os tempos modernos também demonstram que evoluímos da fase industrialista para o momento dos riscos.

A obra beckiana "Risikogesellschaft: Auf dem Weg in eine andere Moderne", lançada no idioma original em 1986 e traduzida para a língua portuguesa como "Sociedade de risco: rumo a uma outra modernidade", publicada apenas em 2010, representa um dos

\footnotetext{
${ }^{1}$ Embora a gênese da noção de pós-modernidade esteja na obra La condition postmoderne, escrita em 1979 por Jean-François Lyotard, na qual se discute as funções e problemas da legitimidade dos discursos e do conhecimento científico, a noção de pós-modernidade não encontra univocidade entre os autores da sociologia contemporânea. Steven Connor (2004), por exemplo, explicita que o prefixo "pós" denomina exaustão ou decadência, típica de um período em que se vive um momento de pós-cultura. Por outro lado, tem-se Zygmunt Bauman (2001), que defende ser o maior dos fatores marcantes das sociedades contemporâneas a liquidez e fragilidade das relações humanas. Ainda, Douglas Kellner (1999) indica que o conceito de pós-modernidade faz menção a um processo de rupturas que abrangem o aspecto histórico, artístico e científico.
} 
maiores contributos para os estudos sociológicos surgidos no interregno do século XX para o século XXI. Com o escrito posteriormente lançado em marcantes versões em inglês e em espanhol, respectivamente nos anos de 1992 e 1998, o alemão se tornou um grande referencial para pautar discussões acadêmicas estabelecidas em torno dos grandes temas presentes na sociedade moderna, especialmente no que tange aos acontecimentos políticos, sociais e jurídicos que certamente marcaram todo um tempo.

O tema lançado pelo alemão em sua obra gira em torno da sociedade industrial, a qual Beck e Zolo (2000) dizem ser caracterizada pela produção e distribuição de bens, mas que foi totalmente substituída pela sociedade de riscos, na qual a ciência e a técnica não possuem qualquer possibilidade de predizer os riscos capazes de abalar a saúde humana e o meio ambiente. Diferentemente do que ocorria naquilo que ele nomeia de "primeira modernidade" - caracterizada pela confiança no progresso e controle dos riscos pela ciência e tecnologia, ainda imaturas -, hoje os riscos não mais correspondem às diferenças sociais, econômicas, políticas ou geográficas de outros tempos.

Desastres ambientais, diárias ameaças nucleares, epidemias e o aumento de conflitos armados são apenas alguns dos exemplos do que Beck (1998) entende que pode ser tratado como risco para a sociedade da pós-modernidade. Segundo ele, na modernidade avançada, a produção social da riqueza caminha lado a lado com a produção social de riscos, ou seja, enquanto a sociedade industrial voltava suas atenções à distribuição de riqueza e aos conflitos surgidos da produção, a sociedade contemporânea deve se preocupar com a produção de riscos de maneira técnico-científica.

Diante desse "estado de modernização" é que a contemporaneidade se encontra eivada de problemas atinentes à distribuição de riquezas e outros que estão ligados à produção e distribuição dos riscos científicos. Na sociedade do risco não é possível manter o desenvolvimento social - a modernização - sem que haja uma produção massiva de riscos, ou, como defende Beck (1998, p. 19), "mientras que en la sociedade industrial la lógica de la producción de la riqueza domina a la 'lógica' de la producción de riesgos, en la sociedad del riesgo se invierte esta relación"².

${ }^{2}$ Tradução livre: "enquanto na sociedade industrial a lógica da produção de
Dessa forma, segundo a teoria de Beck acerca da sociedade de riscos, a mecânica de funcionamento da pós-modernidade é a seguinte: enquanto na sociedade industrial a produção da riqueza é maior do que a produção de riscos, nos tempos hodiernos há uma inversão nessa lógica, ou seja, produzem-se mais riscos do que riquezas, pois são indissociáveis. Significa dizer que as forças produtivas, o progresso técnico e econômico, encontram-se cada vez mais ofuscadas pela produção dos riscos sociais, de tal modo que, para Beck (1998), não se pode desenvolver teses sobre a lógica da produção e distribuição dos riscos sem haver uma comparação com a lógica da distribuição da riqueza.

A partir de catástrofes históricas, como os acidentes nucleares e químicos de Chernobyl ou de Bhopal, Beck compreende que o destino daqueles que vivem atualmente em muito se assemelha a uma espécie de "edad media moderna del peligro" (BECK, 1998, p. 12) em clara referência às desigualdades entre propriedades, grupos étnicos, cidade e campo e nações comuns ao tempo do medievo. Nesse caminho, a transposição da sociedade industrial para a sociedade dos riscos deu espaço aos experimentos nucleares, chamado pelo autor de "la cumbre de las fuerzas productivas y creativas humanas" (BECK, 1998, p. 12), à formação de grupos terroristas até desaguar em ataques organizados, às crises financeiras internacionais e à criminalidade difusa.

Pode-se dizer que a sociedade do risco é indissociavelmente uma constante na pós-modernidade e também um fruto dela: ao mesmo tempo em que pode ser encarada como uma fase de superação de um instante da história humana marcado por avanços breves na ciência e na tecnologia, também pode ser vista como um desencadeamento lógico da própria estrutura da sociedade industrial, que foi responsável pelo incremento na produção de bens e serviços e no consumo humano 3 . Daí afirmar o autor que "los peligros se convierten en polizones del consumo normal" (BECK, 1998, p. 13).

riqueza domina a 'lógica' da produção de riscos, na sociedade de risco essa relação é invertida”.

${ }^{3}$ Para Beck (1998), a sociedade da pós-modernidade aprendeu a construir cabanas e acumular conhecimento útil contra as ameaças da natureza externa. Porém, por outro lado, seguimos praticamente entregues e desprotegidos em face das ameaças industriais. 
Para Beck (1998, p. 25), falar em modernização quer evidentemente se referir

[...] a los impulsos tecnológicos de racionalización y la transformación del trabajo y de la organización, pero incluye muchas cosas más: el cambio de los caracteres sociales y de las biografías normales, de los estilos de vida y de las formas de amar, de las estructuras de influencia y de poder, de las formas políticas de opresión y de participación de las concepciones de la realidad y de las normas cognoscitivas ${ }^{4}$.

Portanto, ao analisar a sociedade contemporânea, Beck a define como sendo a sociedade de riscos. $\mathrm{O}$ autor mostra que o conceito de risco está umbilicalmente relacionado aos efeitos da globalização, uma vez que as ameaças, antes intrínsecas à condição humana, na pós-modernidade ganham vigor e os perigos passam a atingir proporções universais, longe de respeitarem quaisquer fronteiras.

Segundo o escritor, os processos existentes na sociedade pós-moderna são heranças de uma sociedade industrial de riscos, coexistindo nesse meio a pobreza em massa, crises econômicas, guerras vindouras, catástrofes ecológicas, vertentes nacionalistas e fundamentalistas, além da incessante busca pela riqueza. Percebe-se que, na obra beckiana, a modernização deixa de figurar como plano de fundo ou cenário para assumir a posição de problema, já que, na sociedade de riscos, independentemente da classe social a que o indivíduo pertença, ele está exposto a constantes riscos (BECK, 1998, p. 128).

A partir do instante em que os perigos da sociedade contemporânea começaram a surgir, suas ameaças passaram a ser vistas como problemas. Nesse sentido, escrevem Beck, Giddens e Lash (1995, p. 22):

[...] a reflexividade e a impossibilidade de controle do desenvolvimento social invadem as sub-regiões individuais, desconsiderando jurisdições, classificações e limites regionais, nacionais, políticos e científicos. No caso extremo, quando se trata de enfrentar as consequências de uma catástrofe nuclear, não há mais a possibilidade de alguém ser não participante.

Muito embora citemos como exemplos de riscos da pós-modernidade a ocorrência de catástrofes

\footnotetext{
${ }^{4}$ Tradução livre: "[...] aos impulsos tecnológicos da racionalização e da transformação do trabalho e da organização, mas inclui muitas outras coisas: a mudança de caráter social e de biografias normais, de estilos de vida e modos de amar, das estruturas de influência e poder, das formas políticas de opressão e participação das concepções de realidade e normas cognitivas".
}

de origem natural ou humana, a acepção de risco na teoria de Beck parece ser completamente distinta de meras calamidades. Enquanto tragédias desse calibre são conceituadas como acontecimentos que estão delimitados no espaço e no tempo, o risco, por seu turno, é a própria antecipação da catástrofe e se materializa sempre como um acontecimento futuro, que, apenas por meio da "presentificação", ou seja, pela encenação dos riscos globais, é que o futuro das catástrofes se torna presente (BECK et al., 1995, p. 30).

Além do mais, cumpre salientar que, para o referido autor, os riscos são dotados de ambiguidade, possuindo dupla faceta, com certa necessidade de sopesamento entre as oportunidades e as perdas, além de demandarem uma nova divisão de trabalho entre a ciência, a política e a economia (BECK, 2007), meios, ao menos em tese, capazes de refrear a produção de riscos nesse novo contexto social.

Nesse sentido, importante a explicação de Renata Motta (2009, p. 386) acerca da dubiedade dos riscos:

A ambiguidade do risco reside na necessidade de decisão que ele implica: pesar oportunidades e perdas. Toda uma ciência do risco se desenvolveu e nasceu o cálculo probabilístico, a primeira tentativa de controlar o incontrolável. O risco tem uma dimensão de experimentação: não se pode teorizar sobre ele, é da ordem da probabilidade.

Seguindo na contramão da modernização assistida no decorrer do século XIX, na qual o conhecimento deveria ser apreendido com certezas para que pudesse ser administrado numa sociedade tradicional e de pouca compreensão técnica, foi aquela presenciada no curso do século XXI. Isso porque "la modernización ha consumido su opuesto, lo ha perdido y da consigo misma em sus premisas y principios funcionales de sociedad industrial"5 (BECK, 1998, p. 16-17), de modo que a ciência e as técnicas transmitidas da sociedade industrial clássica para a pós-modernidade estão diluídas em um "sistema de coordenadas" e, conforme prediz o autor, a diferenciação entre modernização da tradição e modernização reflexiva ${ }^{6}$ ainda

\footnotetext{
${ }^{5}$ Tradução livre: “a modernização consumiu o seu oposto, o perdeu e se deu suas premissas e princípios funcionais da sociedade industrial”.

${ }^{6} \mathrm{O}$ termo "modernidade reflexiva" é utilizado por Ulrich Beck como sinônimo daquilo que ele também denomina como "segunda modernidade", ou seja, a fase de radicalização dos princípios humanos modernos. Não obstante a utilização da locução por outros autores que são referências na discussão acerca da sociedade do risco, como Giddens e Lash, é possível perceber que
} 
estará em vigor perante a sociedade por muito tempo (BECK et al., 1995, p. 22).

Por outro lado, deve-se levar em consideração que os processos da modernização não são irreversíveis. Ulrich Beck é defensor da tese segundo a qual a sociedade de riscos não conseguiu atingir seu ápice, sendo apenas uma sociedade semi-moderna ${ }^{7}$ (BECK, 1998, p. 20), inclusive analisando, no curso de sua obra magna, as transformações sofridas na estrutura social na passagem do século anterior para o presente - cenário em que os protagonistas foram a consolidação da industrialização e das mudanças que a modernidade implicou na vida cotidiana -, colocando o indivíduo como peça essencial das ações causadoras de riscos.

Diante da importância que os conceitos desempenham na obra de Beck, cumpre-nos rememorar que, além das importantes diferenciações entre noções centrais de seu texto, como risco e catástrofe e risco e valoração cultural do risco, Renata Motta (2009) tece uma tipologia das lógicas de riscos globais, constituída pelos riscos de crises ecológicas, de ameaças terroristas e de crises financeiras globais.

Aliás, o conceito de sociedade do risco na sociologia beckiana é formado por dois momentos distintos, como bem pontuado por Motta (2009, p. 390), o primeiro instante da construção social do risco diz respeito à "reflexividade da incerteza", haja vista que a noção de controle diante das incertezas está fadada ao malogro; o segundo momento, por sua vez, guarda relações com o aspecto "cosmopolita" dos riscos, demonstrando que nem mesmo as fronteiras nacionais são respeitadas pelas ameaças na modernidade. A conclusão a que se chega quando da visualização conjunta desses dois fatores é que os riscos gerados na primeira fase, por assim dizer, não são passíveis de controle social e passam a ser notados como incertezas construídas (MOTTA, 2009).

na obra beckiana as palavras ganham o sentido de que a quebra da sociedade industrializada clássica e a passagem para um novo estágio de vida social não significa o seu fim, mas sim a grande possibilidade de reinvenção da civilização.

${ }^{7}$ Ao citar a sociedade industrial, em seu projeto inicial, como uma "sociedade semi-moderna”, Beck quer dizer que é importante que seu conceito seja revisado, ou seja, de pronto ela não é algo antigo, mas sim uma construção e produto de outros modelos de sociedade. Nesse sentido, explica ele que "a imagem estrutural da sociedade industrial repousa em uma contradição entre o conteúdo universal da modernidade e a estrutura funcional de suas instituições, na qual ela só pode ser realizada de maneira particular e seletiva" (BECK, 1998, p. 20).
Nesse mesmo sentido, é de rigor trazer a lume a contribuição de Assis Machado (2005, p. 45), que faz importantes reflexões sobre a obra de Beck ao identificar as modalidades de risco que se encontram insertas na sociedade contemporânea, nos mesmos moldes feitos pela autora anteriormente comentada. Os riscos podem ser classificados da seguinte maneira:

a) Os riscos das armas de alta destruição, relativos ao poder bélico e aos perigos inimagináveis pelos quais a sociedade está exposta. A propósito, o autor alemão explica que "la amenaza por armas atómicas con unas fuerzas de destrucción inimaginables no cambia"8 (BECK, 1998, p. 84).

b) Os riscos provenientes de perigos globais, nos quais estão enquadrados a destruição ambiental gerada pelo prosseguimento da atividade industrial, bem como a manipulação de bens genéticos e de energia nuclear e química (MACHADO, 2005, p. 45).

c) Por fim, os riscos advindos da situação de pobreza que toma diversos grupos sociais, sobretudo riscos que são relacionados à destruição ecológica, como reflexo do subdesenvolvimento (MACHADO, 2005, p. 45).

Percebe-se, portanto, que as ameaças contemporâneas sequer podem ser comparadas àquelas de outros tempos, em especial por sua lesividade. Fato é que sobrevivemos em uma era artificial, propícia para o incremento dos riscos em dimensões que realmente ultrapassam as barreiras fronteiriças de cada país e terminam por ameaçar a própria humanidade como um todo.

Ainda, há que se dizer que a sociedade está em constante estado de vigilância em virtude da sensação de insegurança que paira sobre os indivíduos viventes da modernidade, sequela daquilo que a professora Mendonza Buergo (2001, p. 02) esclarece ao afirmar que ocorreram mudanças significativas em relação aos perigos do mundo contemporâneo e, hoje, a complexidade organizacional da sociedade dificulta sobremaneira a atribuição da responsabilidade aos envolvidos ${ }^{9}-$ a partir do instante em que ocorre uma

\footnotetext{
${ }^{8}$ Tradução livre: "a ameaça de armas atômicas com forças de destruição inimagináveis não muda”.

${ }^{9}$ Conciliando a questão da sociologia do risco com o direito, em especial o ramo penal, a professora Blanca Mendoza Buergo (2001, p. 226), da Universidad Autónoma de Madrid, relembra que “[...] a estrutura da discussão sobre a configuração atual da dogmática jurídico-criminal, enfatiza-se que a caracterização do direito penal como um direito de risco criminal envolve o
} 
catástrofe ambiental de proporções mundiais, como Chernobyl, dificilmente se individualizará o agente responsável pela explosão e pelo incêndio da usina, ocasionando dois problemas: a falta de punição e o acréscimo ao sentimento de insegurança social.

A conclusão a que se chega a partir de breve análise da sociologia do risco na obra de Ulrich Beck é que os desdobramentos do desenvolvimento científico-industrial que assola a sociedade moderna constitui um complexo de riscos que não podem ser previamente identificados, de modo a serem contidos no espaço-tempo. Além do mais, dado o estado de refém dos indivíduos, não há quaisquer possibilidades de impor a responsabilidade pelos danos causados em virtude dos riscos - que abarcam não apenas riscos ambientais, mas também riscos sociais, já que a desigualdade social e a precariedade das condições de trabalho tendem a crescer na modernidade -, já que não é possível individualizar o autor.

Nesse sentido, infere-se também que o risco na teoria de Beck constitui um estágio intermediário entre a segurança e a destruição (MENDES, 2015, p. 212) e o futuro assume papel de suma importância, na condição de definidor da existência no presente, caracterizado pela localidade e globalidade dos riscos.

Em suma, o autor realiza uma síntese daquilo que considera como consequências da modernidade de riscos ao dizer que

en la modernidad avanzada [...] los problemas y conflictos de reparto de la sociedad de la carencia son sustituidos por los problemas y conflictos que surgen de la producción, definición y reparto de los riesgos producidos de manera científico-técnica ${ }^{10}$ (BECK, 1998, p. 25).

O contributo da teoria da sociedade de riscos de Beck se traduz em demonstrar não apenas que o risco se tornou uma espécie de fator na tomada de decisões na modernidade, mas também que termina por funcionar como nota rememorativa de que todo e qualquer agrupamento social está sujeito aos desafios

recurso a categorias dogmáticas no processo de elaboração conceitual, como tipos de perigo abstrato, à proteção de bens jurídicos supraindividuais de tipo difuso, bem como à flexibilidade e deformalização do direito penal substancial e processual, com vistas a avançar as barreiras da proteção do direito penal, da desmaterialização do conceito de bem jurídico" (tradução livre).

${ }^{10}$ Tradução livre: "[...] na modernidade avançada [...] os problemas e conflitos de distribuição da sociedade da falta são substituídos pelos problemas e conflitos que surgem da produção, definição e distribuição dos riscos produzidos de maneira técnico-científica". e às ameaças da modernidade. A universalização dos riscos não leva em consideração as fronteiras existentes entre as nações, já que, segundo o autor, determinados problemas da nova sociedade preferem aos mais pobres (BECK, 1998, p. 41).

\section{A IDEIA DE SOCIEDADE DE RISCOS NA TEORIA SOCIOLÓGICO DE GIDDENS}

De outro lado, também importante sociólogo que se ateve ao estudo da recente sociedade de riscos, o britânico Anthony Giddens nasceu em 1938 e se tornou mundialmente conhecido a partir da publicação do livro denominado "Novas regras do método sociológico", uma forma de releitura da metodologia sociológica inaugurada nos tempos de Durkheim. Ademais, o autor ganhou mais fama e sua obra prosperou a partir do instante em que assumiu uma posição de crítico das estruturas sociais contemporâneas e, sobretudo, das causas e efeitos da globalização e os riscos dela advindos.

Na concepção giddeniana, a globalização constitui um dos fenômenos sociais de maior importância para a vida contemporânea e que mais despertam o interesse de estudo de sociólogos, a qual resta conceituada pelo autor como a "intensificação da interdependência e das relações sociais mundiais" (GIDDENS, 2001, p. 75). Segundo o sociólogo britânico, a tendência da globalização na modernidade é justamente transformar o mundo em um "único mundo", de modo que, ao mesmo tempo em que as ações de um grupo ocasionam consequências e afetam outros grupos, os problemas mundiais atingem individualmente cada um, provocando a mutação da vida cotidiana (GIDDENS, 2001, p. 52).

Todavia, afirma o autor que a globalização e as mudanças por ela trazidas se traduziram em novas formas de risco, que se diferem daqueles existentes em outras épocas, os quais podiam ter suas causas e efeitos conhecidos, estabelecidos com clareza e, consequentemente, precavidos, enquanto hoje os riscos se tornaram incalculáveis e de consequências indeterminadas (GIDDENS, 2001). Segundo ele, "por constituir um conjunto de processos imprevisíveis, é difícil controlar a globalização, o que leva a novos riscos [...]" (GIDDENS, 2001, p. 51).

Pode-se dizer que, para Giddens (2001), o fenômeno da globalização foi responsável por influenciar 
as tradições e perspectivas culturais de pessoas ao redor do mundo, independentemente de suas origens étnico-sociais, funcionando como fator que impulsionou a escolha por um estilo de vida cosmopolita, que abrange desde a vestimenta até o direito ao lazer e sua consecução. Por outro lado, a globalização, enquanto processo de características abertas e intrinsecamente contraditórias, também trouxe consequências difíceis de serem previstas ou controladas, de modo que, "outra forma de pensar esta dinâmica é em termos de risco" (GIDDENS, 2001, p. 65).

Não é incorreto afirmar que os seres humanos sempre estiveram expostos a riscos das mais variadas naturezas. Porém, como aduz a teoria giddeniana, os riscos na contemporaneidade são mostrados como pertencentes a naturezas diferentes daqueles de outrora, já que há não muito tempo as sociedades se encontravam sob a ameaça dos riscos externos - assim chamados por não decorrerem da ação antrópica, mas sim da própria vontade da natureza, como as catástrofes naturais - e, hoje, apresentam-se os riscos chamados de "manufaturados".

Nesse sentido, explica Giddens (2001, p. 65-66):

Até muito recentemente, as sociedades humanas estavam sob a ameaça de riscos externos - perigos que advêm de secas, terremotos, fome e tempestades que têm origem no mundo natural e não estão relacionados com ação do homem. Hoje em dia, no entanto, somos cada vez mais confrontados com vários tipos de riscos manufaturados - riscos que resultam do impacto da ação do nosso saber e tecnologia sobre o mundo natural. [...] muitos dos riscos ambientais e de saúde com que se deparam as sociedades contemporâneas são exemplos de riscos manufaturados - são um produto da nossa ação sobre a natureza.

Ao escrever "As consequências da modernidade", o autor britânico realiza uma digressão que remonta a existência dos riscos da modernidade às teorias e conselhos advindos dos pais fundadores da sociologia - Émile Durkheim, Karl Marx e Max Weber -, os quais compreendiam naquela época que a modernidade viria a ser uma "era turbulenta" (GIDDENS, 1991, p. 13). A leitura dos problemas dos tempos contemporâneos sob a ótica giddeniana, a partir das considerações que faz sobre os fundadores da sociologia clássica e suas previsões para a modernidade, leva à ideia de que haveria consequências nefastas advindas do trabalho industrial, embora jamais se imaginasse a criação de riscos em virtude do desenvolvimento das forças produtivas ${ }^{11}$.

Nesse sentido, afirma Giddens (1991, p. 13):

[...] todos os três autores viram que o trabalho industrial moderno tinha consequências degradantes, submetendo muitos seres humanos à disciplina de um labor maçante, repetitivo. Mas não se chegou a prever que o desenvolvimento das "forças de produção" teria um potencial destrutivo de larga escala em relação ao meio ambiente material ${ }^{12}$.

Os novos riscos servem à construção social do medo na contemporaneidade e, conforme Giddens, suas principais formas oscilam entre a distribuição objetiva de riscos e aquelas que alteram a vivência ou percepção dos riscos. Em seu escrito sobre os problemas da modernidade, o autor nos ensina que a intensidade de risco é o elemento distintivo entre as várias formas que puderam ser identificadas a partir de acontecimentos dos últimos anos, pois a iminência de "guerra nuclear, calamidade ecológica, explosão populacional incontrolável, colapso do câmbio econômico global, e outras catástrofes globais potenciais, fornecem um horizonte inquietante de perigo para todos" (GIDDENS, 1991, p. 112).

Neste mesmo ponto, Giddens concorda com Ulrich Beck ao citá-lo em sua obra e explicar que os riscos são mesmo globais e não respeitam quaisquer divisões, sejam elas entre ricos e pobres ou até mesmo entre regiões do mundo. $\mathrm{O}$ que acontece é que "Chernobyl está em toda parte" e a intensidade extrafronteiriça de determinadas espécies de risco transcende toda e qualquer diferenciação social e econômica (GIDDENS, 1991, p. 112).

\footnotetext{
${ }^{11}$ Embora Marx e Durkheim fizessem uma previsão de que a sociedade contemporânea teria mais benefícios do que malefícios no que diz respeito à evolução das tecnologias, ambos concordavam que a era moderna seria recheada de turbulências. O alemão, por exemplo, enxergava a luta de classes como fonte de assimetrias na ordem capitalista e também acreditava na superação das necessidades naturais a partir do aperfeiçoamento do uso da técnica, de modo que "o incremento da industrialização somente deveria libertar mais o trabalhador e que nesse rumo a luta de classes estaria com seus dias contados" (ALEXANDRE, 2000, p. 154). Diferentemente, o sociólogo francês afirmava que o êxito da sociedade moderna seria alcançável por meio da industrialização, já que promoveria a solidariedade orgânica entre os membros da sociedade.

${ }^{12}$ Giddens (1991, p. 13) afirma que os riscos de danos ambientais ocasionados por força da industrialização sequer eram pensados pelos sociólogos de outros tempos, o que desaguou em uma profunda dificuldade dos autores contemporâneos - que não só devem estudar esses riscos, mas também encontrar meios de descrevê-los, na vã possibilidade de identificá-los e evitá-los - em desenvolver uma avaliação sistemática desses problemas.
} 
Realizados os breves comentários à menção feita por Giddens aos autores clássicos da sociologia como "profetas" do fatídico futuro de riscos em que estamos inseridos hoje, cumpre-nos salientar que o britânico ainda escreveu sobre as sete formas de caracterização dos riscos na modernidade (GIDDENS, 1991, p. 111-112), cujos perfis podem ser resumidos da seguinte maneira:

a) Em primeiro lugar, Giddens chama a atenção para a "globalização do risco no sentido de intensidade", servindo como exemplos as guerras nucleares, as quais o autor classifica como o mais imediato e catastrófico de todos os perigos globais existentes, pois a detonação de uma ogiva nuclear, ainda que pequena, produziria danos ambientais irreversíveis e colocaria em risco espécies animais complexas e também os seres humanos (GIDDENS, 1991, p. $111)$

b) Sequencialmente, ele identifica a "globalização do risco no sentido da expansão da quantidade de eventos contingentes que afeiam todos ou ao menos grande quantidade de pessoas no planeta", exemplificando com as mudanças na divisão global do trabalho, tais como o incremento acelerado da tecnologia, a diminuição brusca margens de lucro nos últimos anos e a redução da mão de obra (GIDDENS, 1991, p. 112);

c) Em terceiro lugar, Giddens se atenta para o que ele vem a chamar de "risco derivado do meio ambiente criado, ou natureza socializada", existente a partir da infusão de conhecimento humano no meio ambiente material, o que pode ser exemplificado pela manipulação genética de alimentos (transgênicos) e suas nefastas - e já comprovadas cientificamente - consequências para a saúde humana (GIDDENS, 1991, p. 112);

d) $\mathrm{Na}$ quarta posição, o britânico insere os "riscos ambientais institucionalizados", como os mercados de investimentos, capazes de afetar as possibilidades de vida e a concretização dos desejos de milhões de pessoas (GIDDENS, 1991, p. 112);

e) Em quinto lugar, Giddens coloca a "consciência do risco como risco", uma vez que as lacunas de conhecimento acerca dos riscos jamais poderiam ser convertidas em certezas pelo conhecimento religioso (dogmático) ou mágico (sobrenatural). Ou seja, as incertezas ainda não decifradas pelo conhecimento racional e empírico continuam a constituir problemas e riscos para a humanidade (GIDDENS, 1991, p. 112); f) Em seguida, em sexto lugar, o autor insere a "consciência bem distribuída do risco", no sentido de que muito dos perigos enfrentados pelos seres humanos viventes da modernidade, de maneira coletiva, são conhecidos pelo grande público, de modo que não se pode negar que boa parte do mundo reconhece o potencial lesivo de, por exemplo, desastres ambientais ou conflitos armados (GIDDENS, 1991, p. 112). Comentando este tópico da obra giddeniana, segundo Agripa Faria Alexandre (2000, p. 156) afirma se tratar da popularidade do risco, o que provoca certa conclusão ambígua do ponto de vista sociológico, pois, ao mesmo tempo em que a sociedade convive sob a constância de controvérsias acerca das informações dadas - gerando um sentimento de insensibilidade perante os problemas vividos na modernidade -, também há um bombardeamento de informações que dificultam um alarde como contrainvestida ao risco anunciado;

g) Em último lugar, Giddens comenta sobre a "consciência das limitações da perícia", pois hoje nenhum sistema de perícia pode ser inteiramente sábio a ponto de prever as consequências da adoção de princípios peritos (GIDDENS, 1991, p. 112).

Portanto, a abordagem sociológica de Anthony Giddens sobre a sociedade de riscos da modernidade é no sentido de afirmar a existência do risco socialmente construído, o que também legitima a sociedade a discutir os novos valores da modernidade em detrimento daqueles, ainda embrionários, da industrialização primária. Também fica límpido que a crítica giddeniana à sociedade contemporânea repousa sobre a engenharia das sociedades industriais, que se fez baseada em valores materiais, concordando nesse ponto com Beck, de modo que ambos afirmam que a produção de riquezas é impossibilitada se não vier acompanhada de riscos individuais, sociais e ambientais intrínsecos às atividades produtivas: a garantia do bem-estar social se esvaeceu na modernidade e deu lugar aos riscos.

\section{A SOCIEDADE DE RISCOS, AS CONFLUÊNCIAS E AS DIVERGÊNCIAS EM BECK E GIDDENS}

As ideias de Ulrich Beck e Anthony Giddens sobre a existência dos riscos na modernidade, embora apresentem similaridades, também são contrastantes entre si. De fato, as ameaças e as incertezas pertencem às condições gerais da existência humana, de tal 
maneira que resta claro que, não obstante a origem dos riscos ser datada de outros tempos, sobretudo como efeito da quebra do paradigma da sociedade industrial, de distribuição de riquezas, da industrialização primária, tem-se que a modernidade foi responsável por potencializar esses riscos e fez com que nem mesmo fronteiras étnicas, sociais ou geográficas fossem respeitadas.

Conforme pondera Giddens (1991, p. 112), a iminência em que as sociedades contemporâneas vivem de presenciarem guerras nucleares, calamidades ecológicas cada vez mais destrutivas, colapsos (crashes) econômicos e outros riscos, fornece um cenário de catástrofes globais em potencialidade, que não se convola em uma sociedade perigosa apenas para determinadas classes sociais, mas sim para todos, indistintamente. À semelhança da tese giddeniana, como afirmado outrora, Beck (1998, p. 128) compreende que os riscos não respeitam as fronteiras sociais existentes entre aqueles que são privilegiados ou não.

A título exemplificativo de verificação prática dessa sociedade de riscos, inicialmente sob a vertente giddeniana, levanta-se a possibilidade de ocorrência de uma guerra nuclear, cujo potencial destrutivo é inimaginável, com os avanços da ciência e da técnica observados na modernidade, em contraste ao que ocorreu no último conflito mundial assistido. Como Giddens parte do princípio de que a produção dos riscos na sociedade contemporânea é fruto dela própria, como consequências involuntárias e reflexas do nível de avanço científico que os viventes da contemporaneidade atingiram, para ele a guerra seria o marco para a expansão da quantidade de conflitos (ALEXANDRE, 2000, p. 155). Ainda tomando como exemplo prático o início de um conflito armado de nível global, segundo o autor, os riscos fomentaram rápidas mudanças nas relações de trabalho, agindo de forma a acelerar a tecnologia e reduzir as margens de oferta de mão de obra (ALEXANDRE, 2000, p. 155).

Outro exemplo passível de análise são as manipulações genéticas de alimentos, sobre os quais ainda pairam dúvidas sobre a prejudicialidade à saúde humana. Para a tese giddeniana da formação da sociedade dos riscos, esse tipo de experimento científico poderia ser classificado como "provenientes da socialização da natureza” (ALEXANDRE, 2000, p. 155). Conforme Giddens (2001, p. 67), na contemporaneidade, os riscos manufaturados - decorrentes do impacto social produzido pela ação do saber humano e pela tecnologia sobre o mundo social - colocam em risco até mesmo a saúde humana. Como amostra dessa preocupação imediata em relação à saúde do homem na sociedade dos riscos, hoje se pede às pessoas que observem sua exposição ao sol, diante das comprovações quanto aos efeitos maléficos dos raios ultravioletas (GIDDENS, 2001, p. 67).

Dessa forma, vê-se que a semântica do risco está relacionada especificamente com o processo de modernização, no qual as decisões, as incertezas e as probabilidades adquirem maiores significados, mais latentes e determinantes no agir humano. A sociedade dos riscos está relacionada à tematização, no presente, de perigos futuros, percebidos como resultado da civilização.

De outro lado, o tema da sociedade de riscos para Ulrich Beck, como delineado até então, é visto também como decorrência do rompimento com a sociedade industrial primitiva, em que se prezava pela distribuição de bens, serviços riquezas, para dar espaço a uma segunda modernidade, na qual o desenvolvimento da cientificidade e da industrialização é acompanhado pelos riscos (BECK, 1998, p. 25). Os danos da modernidade dos riscos são de tal monta que Beck (1998, p. 128) chega, inclusive, a pensar a possibilidade de cada vez mais os governos se verem obrigados a abandonar seus povos, suas organizações e demais entes, porque não se tem mais controles sobre o que virá a ser a sociedade no momento seguinte.

Similarmente ao realizado a partir das teses giddenianas, podemos tomar como exemplo para a análise das ideias de Beck a problemática da desigualdade social, que, embora existente desde antes dos primórdios da segunda modernidade, em que vivemos, foi aprofundada a partir da manutenção da sociedade de riscos. Para o autor alemão, a precarização do estado da desigualdade social no mundo se dá pelo fato de que os problemas advindos dos processos de modernização ${ }^{13}$ são considerados reflexos de seu tempo, e quanto mais reflexivos os tempos, mais ambígua se torna a sociedade, de modo que «las cuestiones del desarrollo y de la aplicación de tecnologías [...] son

\footnotetext{
${ }^{13}$ Para Beck (1998), a modernização diz respeito ao conjunto de impulsos tecnológicos que propulsionam a racionalização e a transformação do trabalho e a organização social. Além disso, a modernização ainda se reflete na alteração do caráter social, dos costumes, dos estilos de vida e dos modos de se relacionar.
} 
sustituidas por cuestiones de la 〈gestión〉 política y científica [...] de los riesgos de tecnologías a aplicar actual o potencialmente en relación a horizontes de relevancia a definir especialmente ${ }^{14}(\mathrm{BECK}, 1998$, p. 26).

Outro exemplo cabível para análise sob o prisma da concepção de sociedade de risco de Ulrich Beck está também nos perigos inerentes à manipulação científica de alimentos, remédios, na poluição crescente e incontrolável da água, do ar e seus respectivos efeitos sobre os seres vivos, inclusive humanos. Nesse mesmo sentido, tem-se as práticas científicas e os acidentes envolvendo radioatividade (ALEXANDRE, 2000, p. 164), o que demonstra que a natureza deixou de ser um elemento essencial para a satisfação das necessidades e do conforto humano, tornando-se um quase inimigo, por potencializar os riscos produzidos.

A radioatividade, dado seu caráter de fácil propagação e de uma possível globalidade, visto que não se restringe ao local em que o dano foi produzido - a exemplo do ocorrido em Chernobyl, na Ucrânia, cujos resíduos ainda persistem e impossibilitam formas de vida plenas e saudáveis no local -, pode ser enquadrada naquilo que Beck conclui ao dizer que os riscos não mais respeitam às classes sociais. Vivem-se tempos em que a "lógica da produção de riqueza supera a necessidade de se afastar o risco que uma sociedade de risco funda-se com maior reconhecimento e importância" (ALEXANDRE, 2000, p. 164).

Na realidade, com base em uma análise crítica, pode-se ver que a produção da riqueza, de forma desenfreada e impensada, proporciona o aumento dos riscos. Atualmente, pensando como Beck, há notória ausência de certeza e responsabilidade científica sobre questões que infligem diretamente a vivência diária do ser humano, sendo certo afirmar que "quanto mais se desenvolve a sociedade de risco, mais cresce o número de pessoas que são afetadas por ele" (ALEXANDRE, 2000, p. 164).

Como afirmado, hoje é impossível crer que conflitos armados, desastres nucleares e ambientais fiquem restritos ao local em que foram produzidos, já que é notório que, mesmo após anos, alguns dos maiores acidentes nucleares da história, por exemplo,

\footnotetext{
${ }^{14}$ Tradução livre: "as questões do desenvolvimento e aplicação das tecnologias [...] são substituídas por questões da 'gestão' política e científica dos riscos [...] das tecnologias a serem aplicadas atualmente ou potencialmente em relação aos horizontes relevantes a serem definidos. especialmente".
}

continuam a gerar riscos para habitantes da região afetada e de outras, consideravelmente longe. Para utilizar outro exemplo decorrente da própria realidade brasileira, os recentes acidentes envolvendo rompimento de barragens em Minas Gerais demonstram bem as delineações de Beck, visto que ali o dano não respeitou classes socioeconômicas e ainda são verificáveis os efeitos catastróficos dos desastres naquelas regiões, que perdem em termos humanos, econômicos e culturais. Além disso, ecoam notícias de que novos rompimentos podem ocorrer a qualquer momento, o que revela, na prática, a incerteza que as sociedades contemporâneas vivem.

Pensando-se as dimensões em que se observam confluências e divergências nas teorias sobre a sociedade de riscos em Ulrich Beck e Anthony Giddens, pode-se afirmar que ambos os sociólogos trouxeram significativos subsídios para uma compreensão teórica do que se classifica como a sociedade dos riscos. As confluências são inúmeras, como se nota a partir dos exemplos trazidos, sobretudo quanto ao fato de que ambos os autores partem do princípio de que a modernidade é reflexiva, o que significa inferir que os problemas observáveis contemporaneamente são decorrências, reflexos do próprio avanço social. Os exemplos, evidentemente, não destoam entre si, visto que as sociedades nas quais os teóricos viveram não destoam brutalmente entre si, consistindo ambas em verdadeiros produtos dos caracteres da modernidade, o que envolve a produção de danos de caráter ambiental, nuclear, social - como a desigualdade social, a miséria, a fome e as guerras - ou à saúde humana.

Se por um lado Ulrich Beck apresenta certo poder premonitório sobre os problemas de cunho nuclear que viriam a afetar a humanidade nos tempos contemporâneos, principalmente por escrever e lançar a obra em que trata dos pormenores da sociedade de riscos, Giddens demonstra que a produção dos riscos sociais da modernidade é mesmo parte indissociável desse novo projeto de sociedade que se instala paulatinamente, dia pós dia. Para ele, como verificado, os riscos não derivam, em regra, de defeitos ou falhas operatórias humanas, mas são consequências involuntárias e reflexivas do conhecimento social, que avançou estrondosamente.

No mesmo sentido, ainda que ambos os autores teçam suas teses sobre a sociedade de riscos com base no conceito de modernidade reflexiva, Beck 
propõe uma posição mais sóbria desse momento, o que denomina de "vulcão da civilização". Por outro lado, Giddens assegura que os riscos sociais estão impregnados no próprio modo de ser das sociedades contemporâneas, por força da alta complexidade técnica e científica que atingiu.

Outra divergência constatável está no fato de que Beck não concebe mais as ameaças sociais como situações pertencentes a uma ou outra classe, como ocorria ao tempo da sociedade industrial primitiva, em que os danos marcavam de forma mais duradoura as classes menos abastadas economicamente, mas entende que os riscos são produtos simultaneamente reais e irreais, uma vez que se associam os perigos já ocorridos àqueles calculados. Para o britânico, a modernidade é puramente reflexiva e sua ideia não abrange comentários sobre distinções entre classes socioeconômicas e como os riscos as atingem. Representa dizer que, para Giddens, a constituição da modernidade decorre diretamente da produção de informações e da reformulação delas, como meios de agirem em socorro às consequências imprevisíveis da sociedade.

Ambos os autores asseveram que o desenvolvimento científico e industrial contemporâneo é acompanhado por um conjunto de riscos que não podem ser especificados ou refreados no espaço-tempo. Daí Giddens (2001, p. 65) afirmar que "ao contrário dos riscos do passado, que tinham causas estabelecidas e efeitos conhecidos, os riscos de hoje em dia são incalculáveis e de consequências indeterminadas". Tomando por base esse cenário, parte-se da ideia, $a$ priori, de que não há quaisquer possibilidades de se responsabilizar juridicamente alguém pelos danos causados por esses riscos sociais, bem como se impede a recompensa pelos danos às suas vítimas.

Enquanto Beck acusa o desenvolvimento industrial e científico de serem os grandes vilões responsáveis pela produção dos riscos sociais na contemporaneidade, inclusive fazendo alusões à paralisação da sociedade da modernização, bem como à criação de parâmetros aptos a indicar e medir as responsabilidades pelos riscos sociais, como únicos meios capazes de reprimir tais problemas, Giddens toma como guia a reflexão acerca do conceito de uma sociedade produtora de riscos, como elementos intrínsecos à sua constituição.

\section{CONSIDERAÇÕES FINAIS}

A sociedade de riscos é caracterizada primordialmente pelo rompimento com uma estrutura vigente nos últimos séculos, dotada de industrializações primárias, na qual se prezava pela distribuição de bens, serviços e riquezas em geral. Com essa quebra de paradigma, a sociedade da pós-modernidade é posta em um cenário no qual tem que lidar com a incerteza e a incapacidade técnica e científica de conter os mais variados tipos de risco, como conflitos armados a nível mundial, degradações ambientais, disseminação de resíduos radioativos e questões sociais, das quais se destacam a fome e a desigualdade social.

De fato, diante dos avanços da pós-modernidade, tornou-se impossível dissociar a teoria social do conceito de risco e a compreensão de sua extensão, o que confere um papel central do tema na sociologia contemporânea. A razão disso está fundada na emergência dos riscos na pós-modernidade como produto do desenvolvimento desenfreado e impensado da ciência e da técnica, possibilitando a identificação de determinadas características do risco, como a globalidade, que permite que os seus efeitos não fiquem restritos ao local de produção do dano.

Não obstante a existência de outros estudos que digam respeito à análise das questões atinentes à sociedade de riscos, destacam-se os estudos pioneiros e aprofundados dos sociólogos Ulrich Beck e Anthony Giddens sobre o tema. Ainda que os autores apresentem inúmeras semelhanças em suas concepções sobre o risco e a sociedade pós-moderna, como a ideia de que o desenvolvimento científico e industrial é acompanhado por um conjunto de riscos irrefreáveis, algumas distinções também podem ser identificadas. Exemplo marcante é o fato de que a modernidade em Beck deve ser, necessariamente, reflexiva, enquanto Giddens parte da noção de que os tempos atuais são reflexivos, por força da produção massiva de informações, do emprego irredutível da ciência e da técnica, que produzem consequências sociais imprevisíveis.

Outra diferença substancial entre as concepções do risco entre os autores está no fato de que, ao passo em que Giddens concebe uma ideia puramente social do risco, como produto da massificação das relações e dos objetos da contemporaneidade - notadamente a ciência e a informação -, Beck questiona o poder destrutivo e a legitimidade que a sociedade 
pós-moderna forneceu à ciência, que, para ele, é a principal responsável pela produção dos riscos sociais. Essa perspectiva se torna clara na medida em que Beck insere diversos exemplos para ilustrar a complexidade da pós-modernidade dos riscos, ao que coloca os problemas de ordem ambiental e outros que afetam a saúde humana.

Em conclusão, pode-se afirmar que, embora ambos os autores apontem os problemas da pós-modernidade de riscos, com tônica para suas fontes, as formas como são produzidos e seus efeitos catastróficos, ainda buscam preservar uma visão otimista em suas obras sobre a emergência dos valores que visam fornecer o respeito e preservação às vidas. Os dois sociólogos em destaque andam concomitantemente em suas explanações para afirmarem a necessidade de se criarem novos parâmetros para a medição das responsabilidades sociais decorrentes da produção de risco, como forma de uma política radical.

\section{REFERÊNCIAS BIBLIOGRÁFICAS}

ALEXANDRE, Agripa Faria. A dinâmica da sociedade de risco segundo Antony Giddens e Ulrich Beck. Revista GEOSUL, Florianópolis, n. 30, v. 15, 2000.

BAUMAN, Zygmunt. Modernidade líquida. Tradução de Plínio Dentzien. Rio de Janeiro: Jorge Zahar, 2001.

BECK, Ulrich. La sociedad del riesgo: hacia una nueva modernidad. Tradução de Jorge Navarro, Daniel Jiménez e Maria Rosa Borrás. Barcelona: Paidós, 1998.

BECK, Ulrich. Weltrisikogesellschaft: auf der Such nach der verlorenen Sicherheit. Frankfurt: Surhrkamp Verlag, 2007.

BECK, Ulrich; GIDDENS, Anthony; LASH, Scott. Modernização reflexiva: política, tradição e estética na ordem social moderna. Tradução de Magda Lopes. São Paulo: Editora UNESP, 1995.

BECK, Ulrich; ZOLO, Danilo. A sociedade global do risco: uma discussão entre Ulrich Beck e Danilo Zolo. Revista Prima@ Facie, João Pessoa, v. 1, n. 1, jul./dez., p. 1-21, 2002.

CONNOR, Steven. Cultura pós-moderna: introdução às teorias do contemporâneo. 5. ed. São Paulo: Edições Loyola, 2004.

GIDDENS, Anthony. As consequências da modernidade. Tradução de Raul Fiker. 5. ed. São Paulo: Editora UNESP, 1991.

GIDDENS, Anthony. Sociologia. Tradução de Alexandre Figueiredo, Ana Patrícia Duarte Baltazar, Catarina Lorga da
Silva, Patrícia Matos e Vasco Gil. 6. ed. Lisboa: Fundação Calouste Gulbenkian, 2001.

KELLNER, Douglas. Adventures in continental philosophy. In: WATSON, James (Org.). Portraits of american continental philosophers. Bloomington: Indiana University Press, 1999.

MACHADO, Marta Rodriguez de Assis. Sociedade do risco $e$ direito penal: uma avaliação de novas tendências políticocriminais. São Paulo: IBCCRIM, 2005.

MENDES, José Manuel. Ulrich Beck: a imanência do social e a sociedade do risco. Revista Análise Social, n. 214, v. 1., 2015. Disponível em: http://analisesocial.ics.ul.pt/ documentos/AS_214_o01.pdf. Acesso em jan., 2019.

MENDOZA BUERGO, Blanca. El derecho penal en la sociedad del riesgo. Madrid: Civitas, 2001.

MOTTA, Renata. Sociologia de risco: globalizando a modernidade reflexiva. Revista Sociologias, Porto Alegre, ano 11, n. 22, jul./dez., 2009. p. 384-396. 